\title{
História de soterramento e diagênese em arenitos do Grupo Itararé - implicações na qualidade de reservatórios
}

\author{
Luciane Bergamin Bocardi ${ }^{1}$, Sidnei Pires Rostirolla ${ }^{2}$, Midori Graça Fatori Deguchi ${ }^{3}$ \& \\ Fernando Mancini ${ }^{4}$
}

\begin{abstract}
Resumo As condições diagenéticas impostas aos arenitos do Grupo Itararé durante progressivo soterramento foram analisadas com a integração da história de subsidência da bacia e avaliação dos produtos mesodiagenéticos. A história de soterramento e de compactação da coluna sedimentar foi obtida com base em correlações estratigráficas regionais, utilizando-se o registro de perfis compostos, variações de espessura, composição litológica e estimativa de erosão. As idades dos eventos deposicionais e erosivos, com base em trabalhos prévios de cronoestratigrafia, possibilitaram a construção de curvas de geohistória com indicação de fases de subsidência e soerguimento. A deposição do Grupo Itararé relaciona-se a altas taxas de subsidência na Bacia do Paraná. Esta subsidência acentuada teve grande influência na porosidade dos arenitos, principalmente pela ação da compactação química, decorrente do aumento das condições de pressão e temperatura pelo soterramento progressivo. Destaca-se também, o desenvolvimento de crescimentos sintaxiais de quartzo, cimentação abundante por anidrita e dissolução parcial de cimentos e componentes detríticos.
\end{abstract}

\section{Palavras-chave: Diagênese, história de soterramento, Bacia do Paraná.}

\begin{abstract}
Burial history and diagenesis in the sandstones of the Itararé Group - reservoirs quality implications. The imposed diagenetic conditions to the sandstones of the Itararé Group during progressive burial, were analyzed through de integration of subsidence history of the basin with mesodiagenetic products evaluation. The burial history and compaction of the sedimentary column was based on regional stratigraphy correlation, using composite logs, thickness variation, lithology content and erosive rate. The geohistory curves with subsidence and uplift phases were based on previous works of stratigraphy. The Itararé Group deposition was related to high subsidence rate in the Parana Basin. This high subsidence rate had great influence in the sandstones porosity, mainly in chemical compacting action, decurrent of pressure and temperature increase conditions for the burial gradual. Is also distinguished the quartz overgrowths development, abundant anhydrite cementation and partial dissolution of the cements and detritics components.
\end{abstract}

Keywords: Diagenesis, burial history, Paraná Basin.

INTRODUÇÃO Os condicionantes da qualidade de reservatórios arenosos dependem de inúmeros fatores que atuam durante a evolução de bacias sedimentares. Entre os fenômenos que influenciam na diagênese clástica destaca-se a história de soterramento, a qual depende da pressão de sobrecarga, temperatura e fluxo de fluidos sendo também influenciada pela tectônica, magmatismo e taxa de sedimentação. A perda de porosidade devido à compactação mecânica e química depende dos parâmetros sedimentológicos, tais como seleção, empacotamento, composição mineral, bem como da tensão por sobrecarga ocasionada pelo soterramento. Estes fatores são diretamente relacionados com o contexto deposicional e evolução tectônica da bacia (Stonecipher et al. 1984). Com base no registro deposicional e diagenético, pode-se afirmar que durante a evolução termomecânica da Bacia do Paraná, os processos físi- co-químicos alcançaram condições mesodiagenéticas, devido à maior profundidade de soterramento, pressão e temperatura mais elevadas.

A evolução mesodiagenética é influenciada principalmente pela extensão das alterações eodiagenéticas e pela história de soterramento. Neste trabalho o foco principal concentra-se nas alterações mesodiagéticas ocorridas nos arenitos que constituem o Grupo Itararé, decorrentes do progressivo soterramento. O estudo foi realizado com a análise integrada da subsidência da Bacia do Paraná e dos processos diagenéticos que atuaram sobre essa unidade, depositada durante a glaciação permocarbonífera. Estimativas da história de soterramento da bacia, evolução térmica e definição dos produtos mesodiagenéticos do Grupo Itararé foram realizados com base em poços selecionados na parte central da Bacia do Paraná. Á análise da história de so-

1 - Pós-Graduação em Geologia, Programa de Geologia Exploratória, Departamento de Geologia, UFPR e PETROBRAS - UN-RIO/EXP, Curitiba (PR), Brasil. E-mail: lbocardi@ufpr.br

2 - Departamento de Geologia, UFPR, Curitiba (PR), Brasil e Bolsista de Produtividade do CNPq. E-mail: rostirolla@ufpr.br

3 - Programa de Iniciação Científica, Departamento de Geologia, UFPR, Curitiba (PR), Brasil. E-mail: mi_deguchi@yahoo.com.br

4 - Departamento de Geologia, UFPR, Curitiba (PR), Brasil. E-mail: ferman@ufpr.br 
terramento e de compactação da coluna sedimentar em conjunto com os produtos diagenéticos gerados, permite avaliar o impacto da subsidência da bacia e sua influência na redução da porosidade principalmente pelo efeito da compactação.

MÉTODOS A história de soterramento e de compactação da coluna sedimentar foi modelada com base em correlações estratigráficas, espessura das formações e estimativas da erosão. As idades dos eventos deposicionais e erosivos foram definidas utilizando-se trabalhos prévios de cronoestratigrafia (Daemon et al. 1967) e revisão de cartas estratigráficas da Bacia do Paraná (Gama Junior et al. 1982, Zalán et al. 1987, Zalán et al. 1990, Artur \& Soares 2002, Soares 1991, Milani et al. 1994 e Milani 2004). Os gráficos da história de soterramento foram obtidos com o programa computacional específico para modelagem de bacias, aplicado à avaliação de sistemas petrolíferos (BasinMod 1D).

A entrada de dados estratigráficos (Fig. 1) considera as formações e os eventos geológicos, tais como, hiatos e erosão, armazenados no sistema como unidades estratigráficas discretas. Pode-se optar pela utilização da profundidade dos topos das unidades ou espessuras das formações. Os eventos geológicos foram registrados em planilha contendo dados estratigráficos, idades, espessuras das formações, porcentagem dos litotipos e quantidade de material erodido. As propriedades da rocha foram atribuídas para as unidades estratigráficas atuais e para as unidades erodidas de modo que os efeitos da erosão pudessem ser avaliados pelo sistema.

Os cálculos da subsidência são executados em unidades individuais. Nos diagramas da história de soterramento as unidades estratigráficas estão traçadas seqüencialmente, como camadas discretas. Esta aproximação permite a descompactação e o backstripping subseqüente. O programa indica as unidades estratigráficas individualmente em gráficos, o que permite focalizar a atenção em uma determinada formação. Para este estudo, a possibilidade de analisar a evolução da bacia de forma integrada e priorizar uma determinada unidade, é de fundamental importância, pois permite a avaliação de fatores tais como a temperatura versus a profundidade de soterramento na unidade selecionada.

$\mathrm{Na}$ construção do modelo de compactação definem-se os percentuais de cada litotipo que compõem as unidades a serem avaliadas. O modelo mais indicado para rochas siliciclásticas foi proposto por Sclater \& Christie, 1980. A compactação gradual das camadas com o soterramento é obtida com base na diminuição do espaço poroso com o aumento da profundidade.

Para análise da história de soterramento foram selecionados 45 poços, da Bacia do Paraná, contendo registros de unidades estratigráficas mais recentes até unidades mais antigas, depositadas na porção central da bacia (Fig. 2).

A técnica de backstripping tem sido amplamente aceita no estudo de bacias de margem passiva, embora seja controverso seu uso em bacias intracratônicas. Esta aparente dicotomia advém da dificuldade em estabelecer os parâmetros para análise da subsidência em bacias intracratônicas, principalmente a idade dos horizontes, dados paleobatimétricos e a quantidade de material removido por erosão. Entre os fatores mais importantes, destaca-se a dificuldade na estimativa das erosões subseqüentes aos períodos de subsidência, que é fato em bacias intracratônicas devido a sua longa história evolutiva.

Considerando estes aspectos, as curvas de subsidência foram elaboradas, a partir de estimativas de erosão, fundamentadas em análises estratigráficas regionais e correlação entre poços profundos. A espessura de material erodido das Formações Ponta Grossa e Pirambóia foi estabelecida por meio de correlações, com base principalmente em perfis de raios gama e resistividade, comparados com os perfis das unidades de poços adjacentes. A erosão subseqüente aos derrames basálticos foi estimada em $20 \mathrm{~m} / \mathrm{Ma}$, com base em Németh et al. (2003). A erosão após a deposição do Grupo Bauru foi estimada em $20 \%$ em relação à espessura preservada nos poços. Um exemplo da correlação utilizado para a estimativa de erosão da Formação Ponta Grossa, que compõe a seção devoniana da bacia pode ser observado na figura 3.

Para integração dos dados obtidos com a análise de subsidência, história térmica, avaliação da redução da porosidade por compactação e produtos diagenéticos, gerados com o aumento da profundidade de soterramento, foram utilizados 10 poços da Bacia do Paraná. Estes poços foram escolhidos devido a qualidade e quantidade de dados disponíveis, tais como perfis de raios gama, resistividade, sônico e testemunhos de sondagem, com amostras em intervalos representativos.

A caracterização diagenética do Grupo Itararé foi analisada com base em amostras de arenitos obtidas de testemunhos de sondagem realizados na Bacia do Paraná em intervalos de profundidade situados entre $300 \mathrm{~m}$ a $4700 \mathrm{~m}$ (Bocardi, 2005; Bocardi et al.2006). A diagênese abrange os processos físicos, químicos e biológicos que ocorrem após a deposição dos sedimentos.

\section{Entrada}

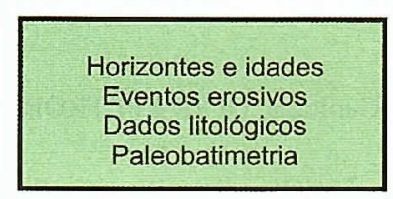

Modelagem

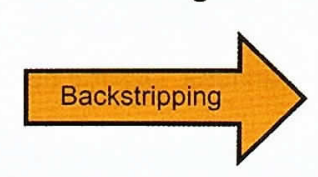

Saída

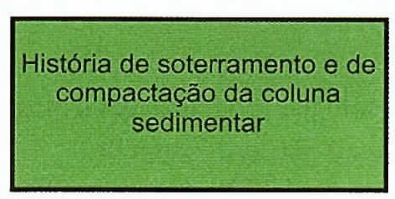

Figura 1 - Fluxograma básico para modelagem da história de soterramento. 


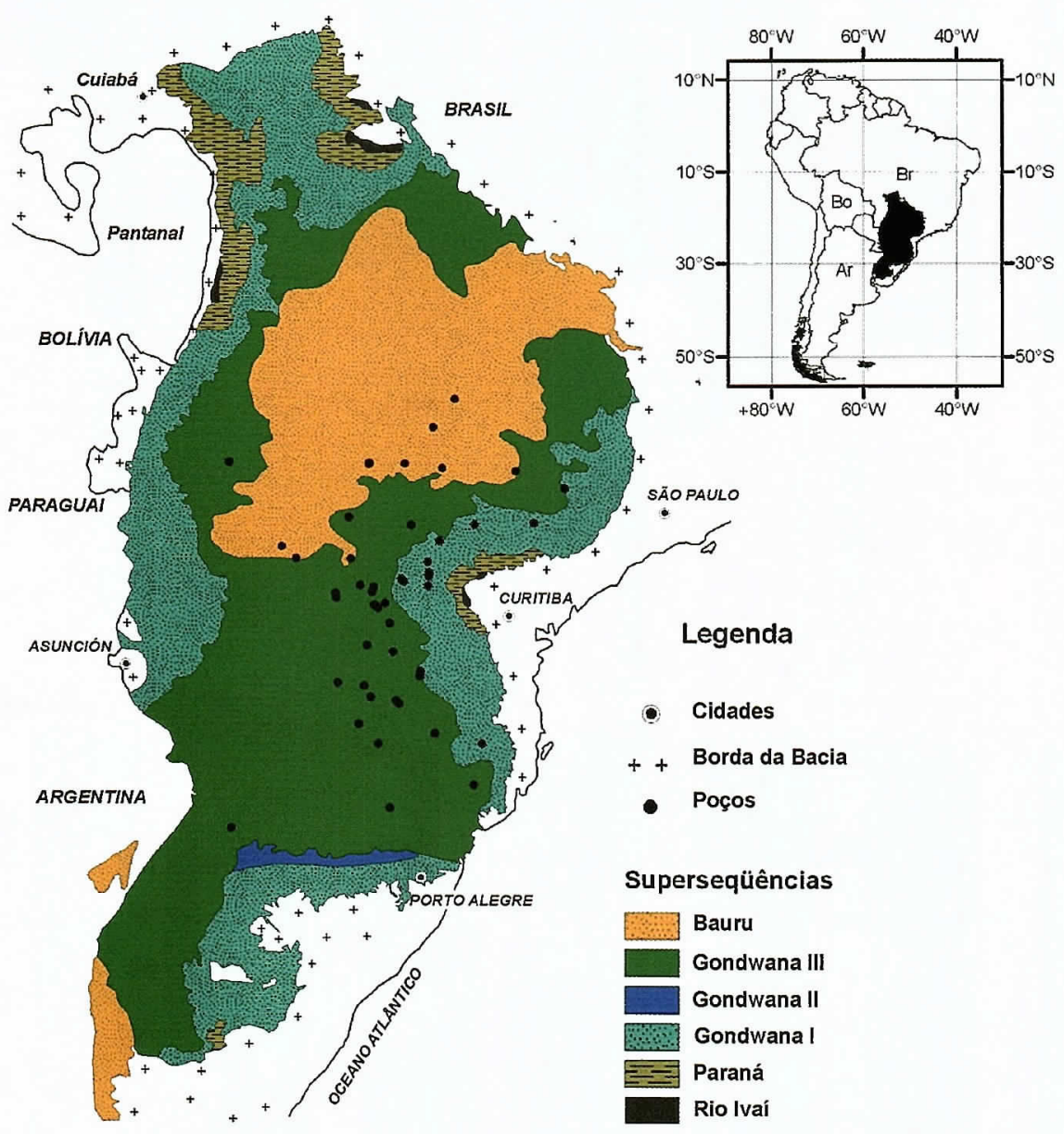

Figura 2 - Mapa geológico simplificado da Bacia do Paraná, com o contorno estrutural (profundidade) do embasamento cristalino e localização dos poços utilizados para análise da história de soterramento (Fonte do mapa: Milani 2004).

Estes processos são ativos durante a evolução da bacia e relacionam-se entre outros fatores à temperatura, pressão e química dos fluidos durante a história deposicional, soterramento e soerguimento (Fig. 4).

A análise integrada da história de soterramento e diagênese possibilitou a avaliação do impacto da subsidência da bacia e sua influência na qualidade dos arenitos como potenciais reservatórios do Grupo Itararé. Os constituintes detríticos e diagenéticos que compõem os arenitos foram identificados com microscópio óptico de luz transmitida. Análises por difração de raios $\mathrm{X}$ foram utilizadas para auxiliar na identificação de argilominerais. As relações entre os minerais foram detalhadas com microscópio eletrônico de varredura. Gráficos quantitativos do volume intergranular versus cimentação foram usados na avaliação da importância relativa dos processos de compactação e cimentação na redução da porosidade (Houseknecht, 1987).

Perfis sônicos foram utilizados para calcular a porosidade, considerando o tempo de trânsito da onda sonora na rocha, com os parâmetros de 55,5 para o tempo de trânsito na matriz e 189 para o tempo de trânsito no fluido. A porosidade foi obtida em vários intervalos de profundidade, para avaliar os efeitos da compacta- ção e validar os resultados obtidos com a modelagem.

Considera-se neste estudo que a eodiagênese corresponde ao intervalo de profundidade de 0 a $2 \mathrm{~km}$, temperatura até $70^{\circ} \mathrm{C}$ e inclui as alterações químicas controladas pelas condições ambientais que ocorrem próximo à superfície. A mesodiagênese refere-se às alterações diagenéticas sob soterramento superior a $2 \mathrm{~km}$ e temperatura acima de $70^{\circ} \mathrm{C}$ e a telodiagênese ocorre em seqüências que estiveram sob condições eodiagenéticas e/ou mesodiagenéticas e foram posteriormente soerguidas (Morad et al., 2000).

CONTEXTO GeOlógico A Bacia do Paraná é constituída por uma sucessão sedimentar-magmática com idades entre o Neo-Ordoviciano (465 Ma) e o Neocretáceo (65 Ma). Seis unidades de segunda ordem fazem parte de seu arcabouço estratigráfico (Fig. 5). Estas unidades foram denominadas Superseqüência Rio Ivaí, Superseqüência Paraná, Superseqüência Gondwana I, Superseqüência Gondwana II, Superseqüência Gondwana III e Superseqüência Bauru (Milani, 1997). Na carta estratigráfica publicada por Milani (2004), (Fig. 5), a Superseqüência Rio Ivaí marca a sedimentação inicial da Bacia do Paraná, com idade de $443 \pm 10 \mathrm{Ma}$, 


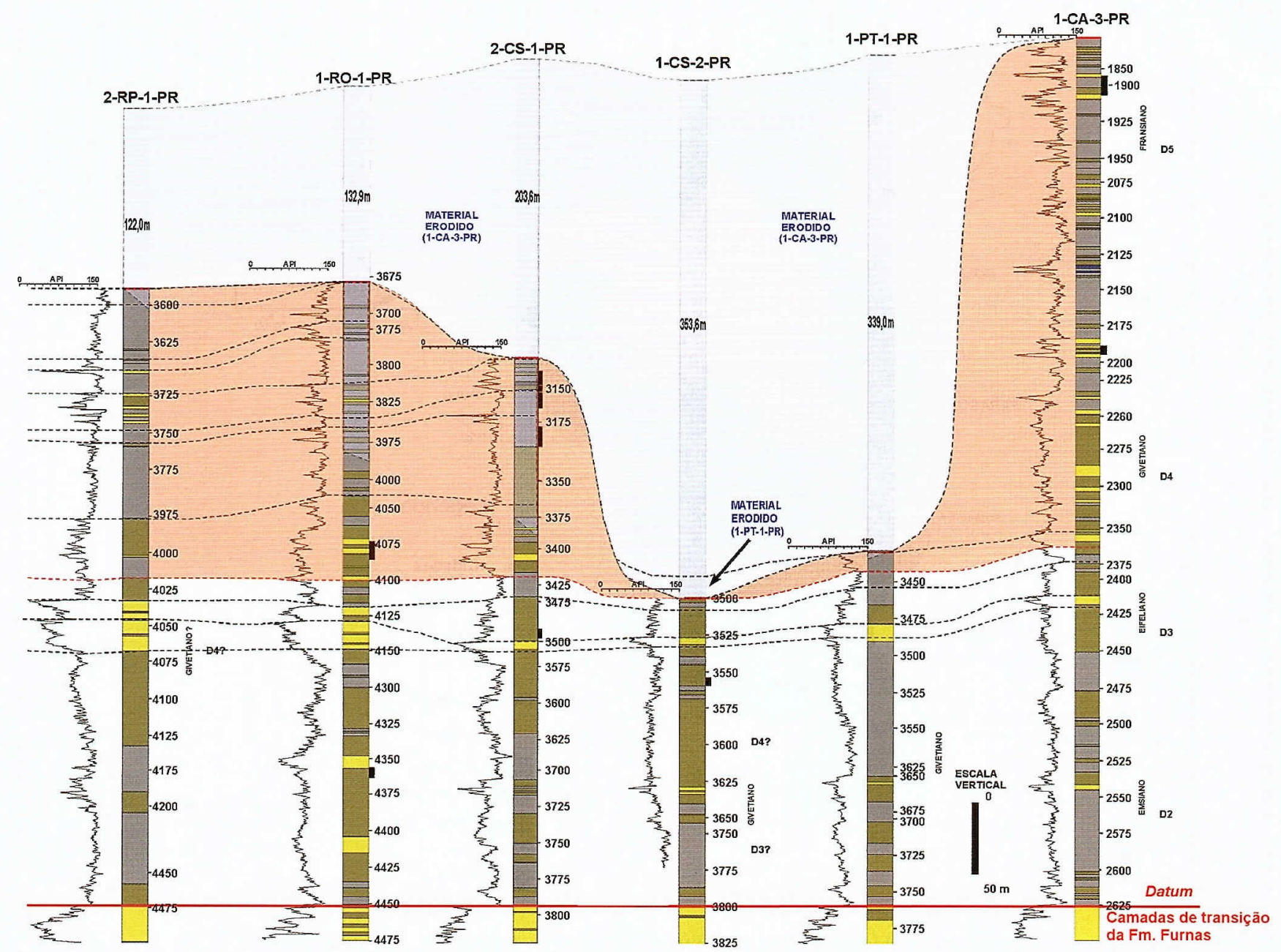

Figura 3 - Correlação estratigráfica em poços da seção devoniana da Bacia do Paraná, Fm. Ponta Grossa.

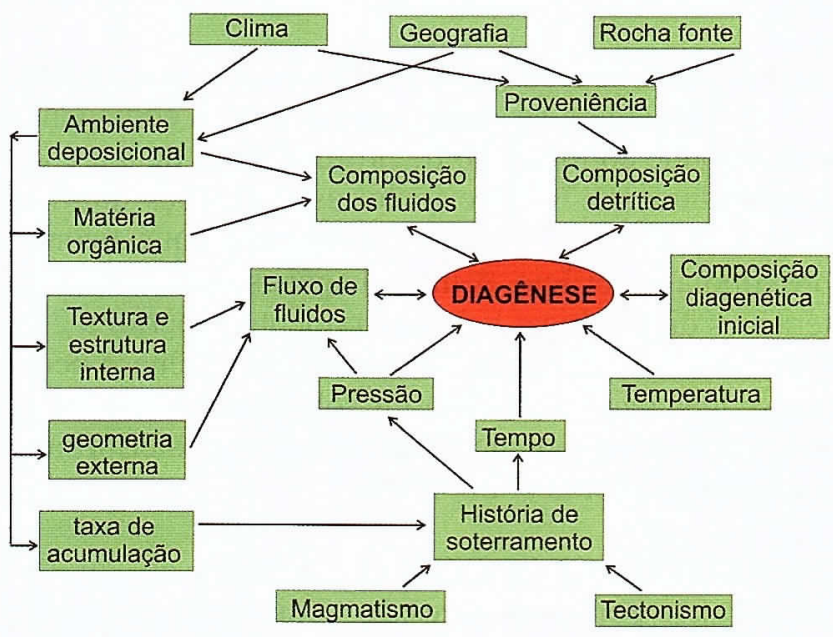

Figura 4 - Parâmetros que influenciam na diagênese clástica (modificado de Stonecipher et al. 1984).

determinada pela datação do Basalto Três Lagoas com base no método Ar/Ar. Para a Formação Vila Maria, unidade superior da Superseqüência Rio Ivaí, a idade obtida é de 435,9 \pm 7,8 Ma (Mizusaki et al. 2002, por meio de datação $\mathrm{Rb} / \mathrm{Sr}$ ).

A Superseqüência Paraná iniciou com os depósitos areno-conglomeráticos da Formação Furnas, eodevoniano (410 Ma), recobertos por pelitos fossilíferos da Formação Ponta Grossa (Emsiano-400 Ma/Frasniano-375 Ma). A camada devoniana exibe espessura máxima preservada em torno de 850 metros na porção brasileira da Bacia do Paraná.O limite entre os estratos devonianos e carboníferos se expressa como uma superfície discordante com um hiato de cerca de $50 \mathrm{Ma}$. A subsidência no Carbonífero ocasionou a deposição de espessa seção com até 1500 metros de rochas sedimentares das unidades Aquidauana-Itararé. A deposição do Grupo Itararé foi influenciada inicialmente pela fase de subsidência atribuída à sobrecarga das geleiras continentais, seguida pelo peso dos sedimentos depositados durante o ciclo transgressivo-regressivo subseqüente (Zalán et al. 1987).

No Mesozóico, a Bacia do Paraná foi submetida a um período de quiescência tectônica prolongada, interrompido pelos movimentos da "Reativação Wealdeniana" e ruptura do Gondwana, no início do Cretáceo. O contato entre as formações Rio do Rasto/Pirambóia e Botucatu consiste em discordância erosiva com um hiato deposicional de aproximadamente $100 \mathrm{Ma}$ de du- 


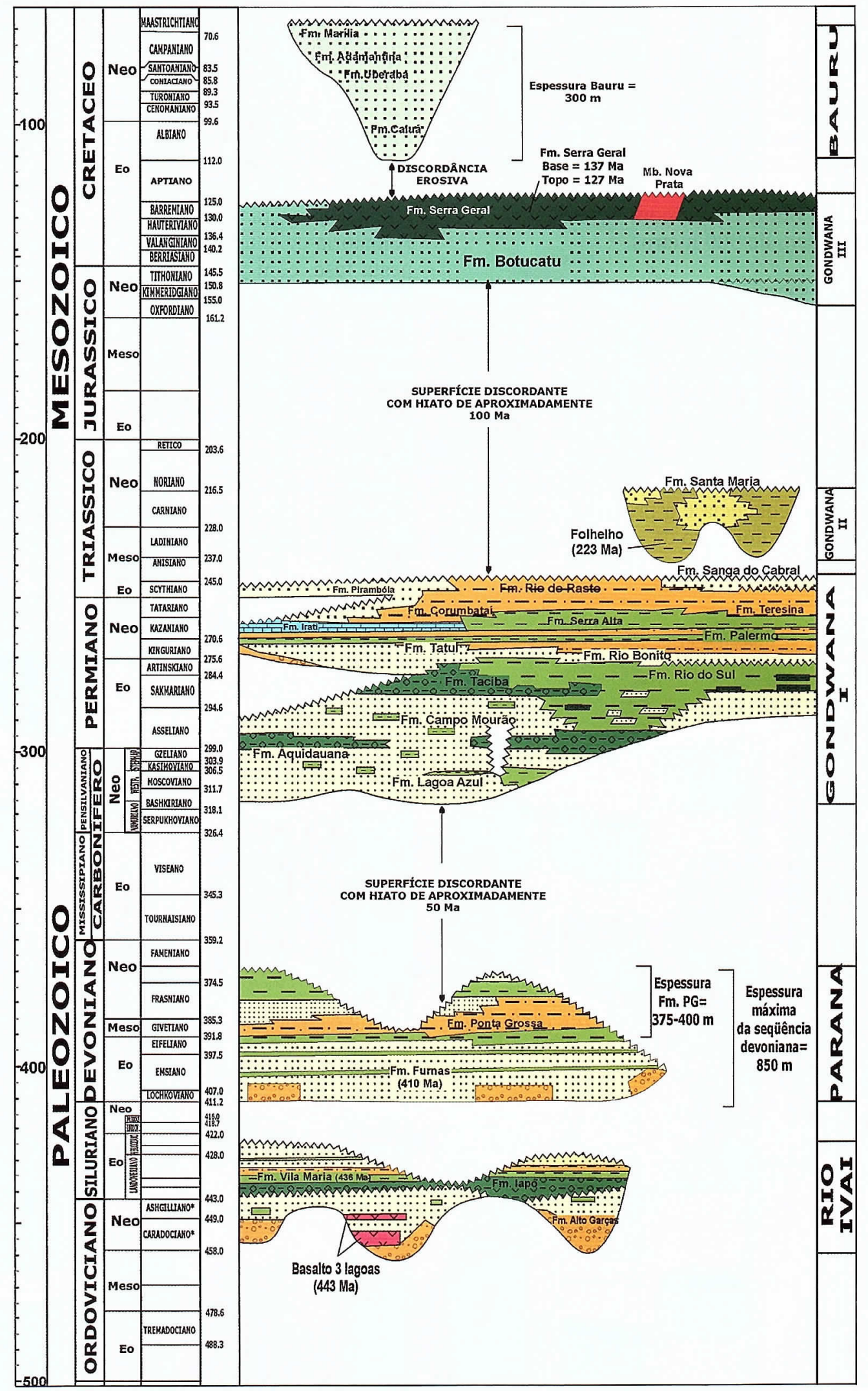

Figura 5 - Carta cronoestratigráfica da Bacia do Paraná (Modificado de Milani 2004).

ração. Durante o Triássico, uma área particular no sul da Bacia do Paraná, acomodou a seção flúvio-lacustre da Superseqüência Gondwana II (Milani, 1997), de idade meso a neotriássica denominada Formação Santa Maria.
O rifteamento sul-atlantiano responsável pela ruptura do Gondwana ocidental envolveu o embasamento da bacia. Suturas antigas foram reativadas seguidas pela geração de novos conjuntos de falhas e fraturas, que propiciaram a injeção e o extravasamento 
de grandes volumes de rochas ígneas, com espessura próxima a 2000 metros no depocentro. Em termos geocronológicos Turner et al. (1994) estudaram amostras coletadas em diferentes níveis dentro da seção de lavas cujos resultados, baseados em $\mathrm{Ar} / \mathrm{Ar}$, posicionaram o evento Serra Geral entre 137 e 127 Ma. A Superseqüência Bauru (Milani, 1997), assenta em discordância sobre os basaltos Serra Geral, com espessura máxima preservada da ordem de 300 metros.

HISTÓRIA DE SOTERRAMENTO A história de soterramento e de compactação da coluna sedimentar, obtida por correlações estratigráficas, espessura das formações e estimativas da erosão, evidencia quatro fases de subsidência na Bacia do Paraná (Figs. 6, 7, 8 e 9). Na primeira fase de subsidência destaca-se a deposição da seqüência Rio Ivaí (Ordoviciano), que corresponde à sedimentação inicial da Bacia do Paraná. Entre a deposição desta seqüência e a próxima, denominada Seqüência Paraná, há um hiato de aproximadamente 12
Ma. A segunda fase de subsidência corresponde a deposição da Seqüência Paraná, no Devoniano, com espessura máxima de $850 \mathrm{~m}$. Entre a deposição da Seqüência Paraná e a seguinte há uma superfície discordante com hiato de aproximadamente 50Ma. A terceira fase de subsidência, do Permocarbonífero até o início do Triássico é marcada pela deposição da Seqüência Gondwana I, com espessura total da seqüência em torno de $2400 \mathrm{~m}$. A história de soterramento do Grupo Itararé tem início nesta fase, com a deposição de $1500 \mathrm{~m}$ de sedimentos registrados na porção central da bacia. Após a deposição da Seqüência Gondwana I, desenvolveu-se uma superfície discordante com hiato de aproximadamente $100 \mathrm{Ma}$, que expôs os sedimentos do Grupo Itararé a eventos erosivos. A quarta fase de subsidência durante o Neojurássico ao Eocretáceo foi influenciada pela sobrecarga, decorrente do magmatismo basáltico que afetou a Bacia do Paraná e corresponde à Sequência Gondwana III. Após aproximadamente $13 \mathrm{Ma}$ do final da fase de magmatismo, depositou-se a Seqüência Bau-

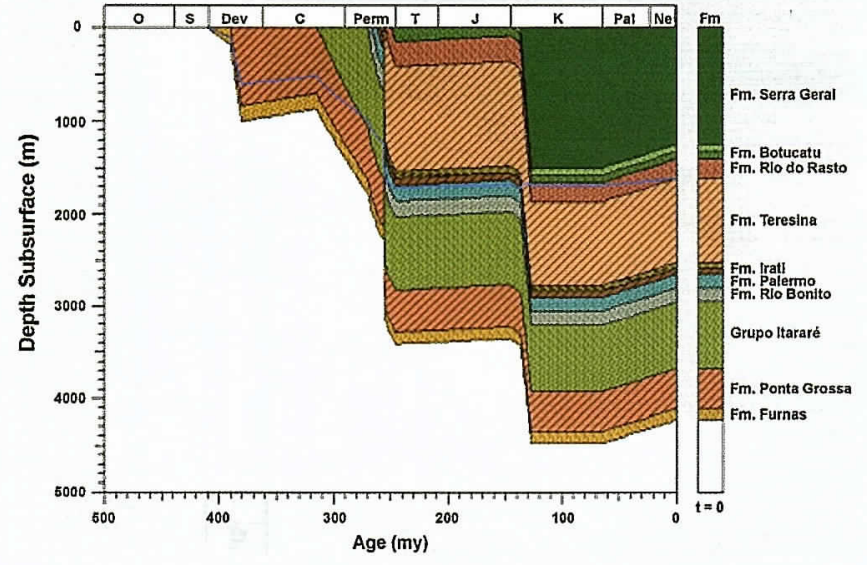

Figura 6 - História de soterramento da Bacia do Paraná com dados estratigráficos do Poço 1-RO-1-PR. A linha azul corresponde a subsidência tectônica.

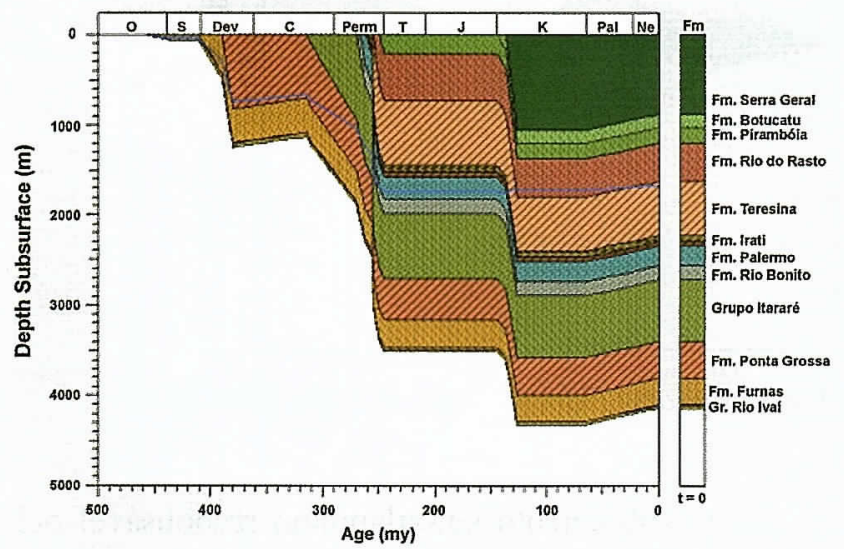

Figura 7 - História de soterramento da Bacia do Paraná com dados estratigráficos do Poço 2-RP-1-PR. A linha azul corresponde a subsidência tectônica.

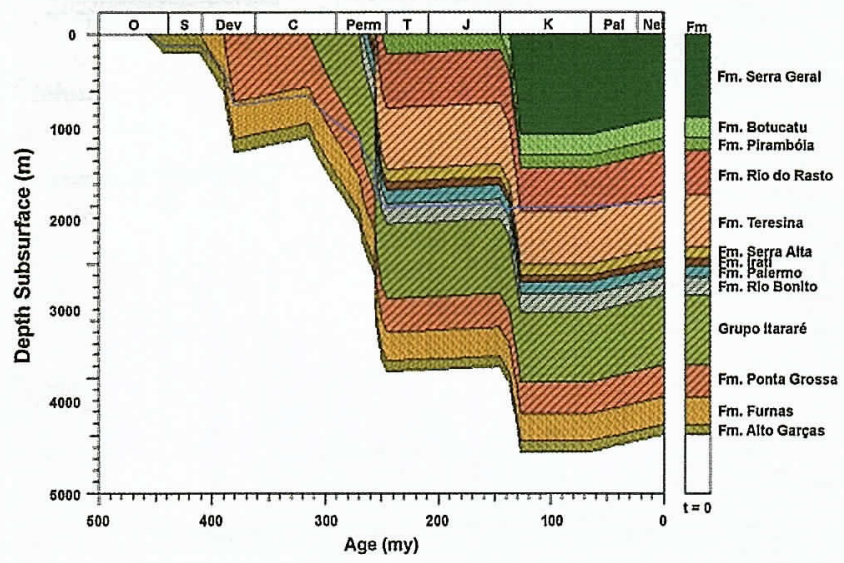

Figura 8 - História de soterramento da Bacia do Paraná com dados estratigráficos do Poço1-RS-1-PR. A linha azul corresponde a subsidência tectônica.

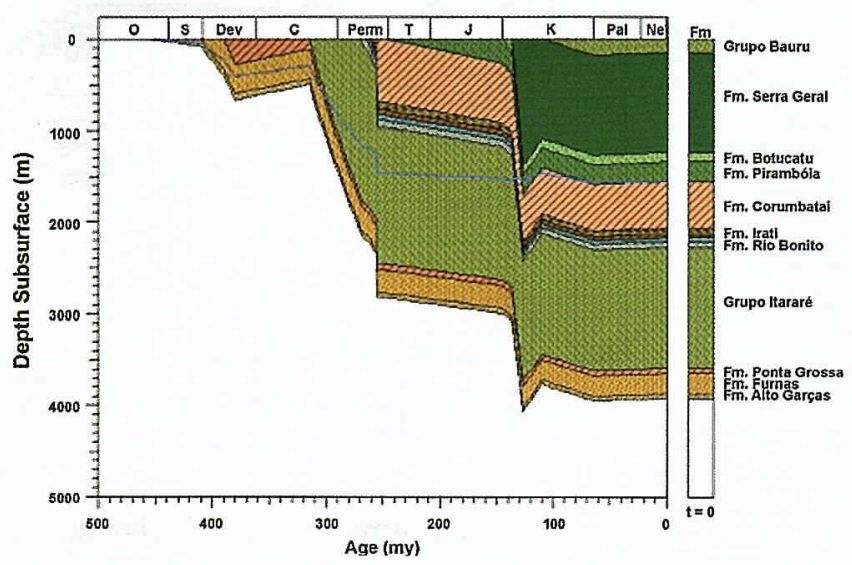

Figura 9 - História de soterramento da Bacia do Paraná com dados estratigráficos do Poço 2-LA-1-SP. A linha azul corresponde a subsidência tectônica. 
ru, com espessura aproximada de $300 \mathrm{~m}$.

CARACTERIZAÇÃO DIAGENÉTICA Os arenitos que constituem o Grupo Itararé apresentam grande heterogeneidade composicional, entretanto algumas características são mais freqüentes. Destacam-se os arenitos de granulação fina à média, constituídos por quartzo, feldspatos e fragmentos líticos e arenitos constituídos essencialmente por quartzo. Feldspatos detríticos ocorrem parcialmente dissolvidos e freqüentemente são substituídos por caolinita e anidrita mesodiagenéticas. Fragmentos de rochas metamórficas, plutônicas, vulcânicas e sedimentares, tais como, arenitos e intraclastos argilosos são constituintes detríticos comuns (Bocardi 2005; Bocardi et al. 2006).

Os produtos eodiagenéticos incluem siderita, calcita, caolinita e óxido de ferro. Apesar de estarem presentes em diferentes fácies deposicionais, os constituintes formados durante a eodiagênese, apresentam significativa variação na quantidade e distribuição.

Na mesodiagênese os principais produtos gerados foram a cimentação por quartzo, anidrita, calcita, dolomita, clorita, ilita e dickita. Quartzo é o constituinte diagenético mais abundante. Ocorre como crescimentos sintaxiais que cobrem parcial ou completamente os grãos detríticos e desenvolvem-se preferencialmente quando não há cimentação precoce de calcita e/ou siderita. Crescimentos sintaxiais de quartzo são formados na mesodiagênese (Morad et al., 2000), à temperatura entre 90 a $130{ }^{\circ} \mathrm{C}$ e profundidade em torno de $3000 \mathrm{~m}$ (Giles et al.,1992). A sílica necessária para formação dos crescimentos sintaxiais de quartzo provém da dissolução por pressão em grãos de quartzo sob soterramento (Wilson \& Stanton, 1994). Nos arenitos que constituem o Grupo Itararé a dissolução por pressão ao longo dos contatos entre grãos de quartzo atuou como fonte de sílica considerável para formação de crescimentos sintaxais de quartzo durante a mesodiagênese
(Fig. 10).

A cimentação por anidrita ocorre na forma de cristais poiquilotópicos distribuídos em grandes poros, porém ocorre também como cristais menores, em espaços intergranulares. Os contatos entre cimentos de anidrita e carbonáticos, sugerem precipitação contemporânea, embora ocorram cristais de anidrita englobando cristais de carbonato, o que pode indicar uma fase de precipitação posterior (Bocardi, 2005; Bocardi et al. 2006).

A cimentação por calcita cristalina grossa, preenche frequentemente as fraturas de arenitos com empacotamento fechado. Neste caso relaciona-se a um estágio de progressivo soterramento (Morad et al., 1990). Dolomita e clorita ocorrem como preenchimento de poros de dissolução, relacionada à fase de precipitação mesodiagenética (Bocardi 2005; Bocardi et al. 2006). Ilita, frequentemente observada nos arenitos do Grupo Itararé, é associada à temperatura superior a $70^{\circ} \mathrm{C}$, tornando-se pervasiva a partir de $130^{\circ} \mathrm{C}$ (Morad et al., 1990; Giles et al., 1992). A origem da caolinita mesodiagenética é relacionada ao fluxo de ácidos orgânicos durante este estágio (Surdam et al., 1984). Outro aspecto é a transformação parcial da caolinita em dickita com o aumento da temperatura e profundidade de soterramento (Morad et al. 1994), que ocorre à temperatura aproximada de $80^{\circ} \mathrm{C}$ (Ehrenberg et al., 1993).

QUALIDADE DE RESERVATÓRIOS O Grupo Itararé apresenta espessura máxima de aproximadamente $1500 \mathrm{~m}$ e profundidade de soterramento em torno de 4000m (Figs. 6, 7, 8 e 9). A sedimentação desta unidade iniciou no período Carbonífero, com a deposição de sedimentos sob influência glacial formando um conjunto heterogêneo de fácies deposicionais. A influência do ambiente glacial e subglacial, durante a deposição é indicada pela seleção pobre a moderada, tamanhos de grãos variáveis e diferentes graus de arredondamento.

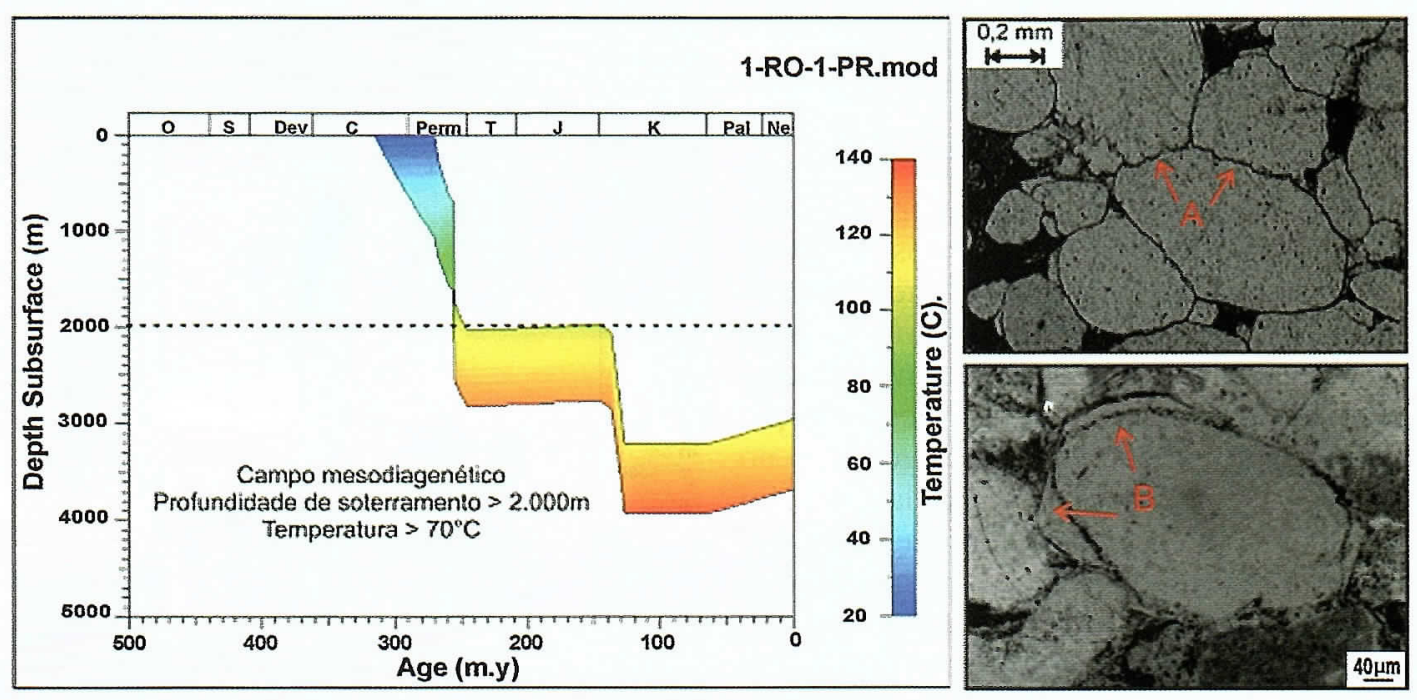

Figura 10 - Gráfico com a profundidade de soterramento e temperatura do Grupo Itararé. Fotos obtidas com microscópio óptico de luz transmitida. A - Contatos suturados entre grãos de quartzo, decorrentes da compactação química. B - Crescimentos sintaxiais de quartzo. 
O processo de compactação mecânica pode ser diagnosticado pela deformação de fragmentos líticos e intraclastos argilosos e foi facilitado pela constituição detrítica.

Após a fase principal da compactação mecânica e ao início da compactação química, a temperatura e os fluidos da bacia exercem maior controle sobre as alterações diagenéticas. A evolução química e isotópica dos fluidos ocorre durante o soterramento progressivo. Além do fraturamento contínuo dos grãos detríticos, ocorrem várias modificações diagenéticas, tais como a cimentação, transformação mineral, dissolução de grãos e cimentos e compactação química (Fig. 10). A transformação mineral atinge principalmente os minerais da argila e os feldspatos detríticos. Os principais fatores que condicionam as alterações mesodiagenéticas são a extensão e distribuição das alterações eodiagenéticas, tempo de residência em determinadas condições de pressão e temperatura e maturação térmica da matéria orgânica e formação dos ácidos orgânicos nos folhelhos próximos.

Durante a deposição da seqüência permocarbonífera ocorreram as maiores taxas de subsidência na Bacia do Paraná, a qual teve grande influência na redução da porosidade pelo efeito da compactação. Com a evolução termomecânica da bacia os processos físicoquímicos passam a atuar sob o regime mesodiagenético, onde as alterações são controladas pelo aumento da pressão e temperatura decorrentes da maior profundidade de soterramento.

Quanto ao tempo de residência sob condições de soterramento efetivo, os gráficos da história de soterramento obtidos em poços localizados em porções mais profundas da bacia, mostram que o Grupo Itararé atingiu o estágio mesodiagenético, com profundidade de soterramento aproximada de $2000 \mathrm{~m}$, no Permiano (Figs. 6, 7 e 8). Nestes poços a evolução da história de soterramento evidencia que ao atingir profundidade próxima a $2000 \mathrm{~m}$, o Grupo Itararé permaneceu sob estas condições diagenéticas durante o Triássico e Jurássico. Após a deposição da Seqüência Gondwana I (Fig. 5), ocorrem registros de uma superfície discordante com hiato de aproximadamente $100 \mathrm{Ma}$. Porém, ainda durante o Triássico e Jurássico nas porções mais rasas da bacia, o Grupo Itararé encontrava-se em menor profundidade de soterramento (Fig. 9). Com os dados do poço 2-LA-1-SP e adjacentes, observa-se que durante o Triássico e Jurássico parte dos arenitos do Grupo Itararé estiveram sob influência de fluxo de fluidos meteóricos, principalmente nas camadas superiores. Nestes poços o Grupo Itararé atingiu o estágio mesodiagenético no início do Cretáceo, quando a subsidência da bacia foi acentuada pela sobrecarga decorrente do magmatismo.

O fluxo de fluidos meteóricos em seqüências siliciclásticas que já haviam sido submetidas a condições de soterramento efetivo, implica em modificações telodiagenéticas, que inclui a dissolução de minerais, em geral de feldspatos, fragmentos líticos e cimentos carbonáticos. Após a dissolução de constituintes instáveis ocorre a precipitação de novos cimentos, influen- ciada pela mudança das condições geoquímicas. Estas condições decorrentes do soerguimento do Grupo Itararé durante o Triássico e Jurássico poderiam explicar a cimentação abundante por anidrita observada nos arenitos.

O desenvolvimento da porosidade secundária também foi influenciado pelos fluxos de fluidos próximos à superfície neste período. Este processo foi provavelmente acentuado devido à ação de ácidos orgânicos liberados durante a fase inicial de maturação da matéria orgânica das rochas geradoras da bacia (França \& Potter, 1989). Esta fase corresponde do Neojurássico ao Eocretáceo, quando a Bacia do Paraná foi afetada por uma anomalia térmica regional, decorrente do processo de abertura do oceano Atlântico, que resultou em nova fase de subsidência. Neste período os depósitos que ainda estavam sob influência de fluxos meteóricos, foram submetidos a condições de soterramento mesodiagenético.

A profundidade máxima de soterramento, aproximadamente $4000 \mathrm{~m}$ na maioria dos poços utilizados, corresponde à temperatura próxima a $130^{\circ} \mathrm{C}$ (Fig. 11), que implica em modificações mesodiagenéticas, as quais coincidem com o início da compactação química, reações de transformação de argilominerais, cimentação de quartzo e alteração térmica da matéria orgânica. A compactação química, que resulta da dissolução por pressão dos grãos ao longo dos contatos tangenciais, afetou principalmente os grãos de quartzo.

Em decorrência do efeito do soterramento, embora a porosidade predominante nos arenitos analisados seja secundária, gerada pela dissolução de grãos instáveis e de cimentos, destaca-se que o sistema poroso foi fortemente influenciado pela dissolução por pressão, evidenciado pela freqüência de contatos suturados. Outro aspecto que contribui para redução da porosidade nestas rochas é a cimentação por crescimento sintaxial de quartzo, bem desenvolvida principalmente em quartzoarenitos.

Considerando a idade, conteúdo de quartzo de-

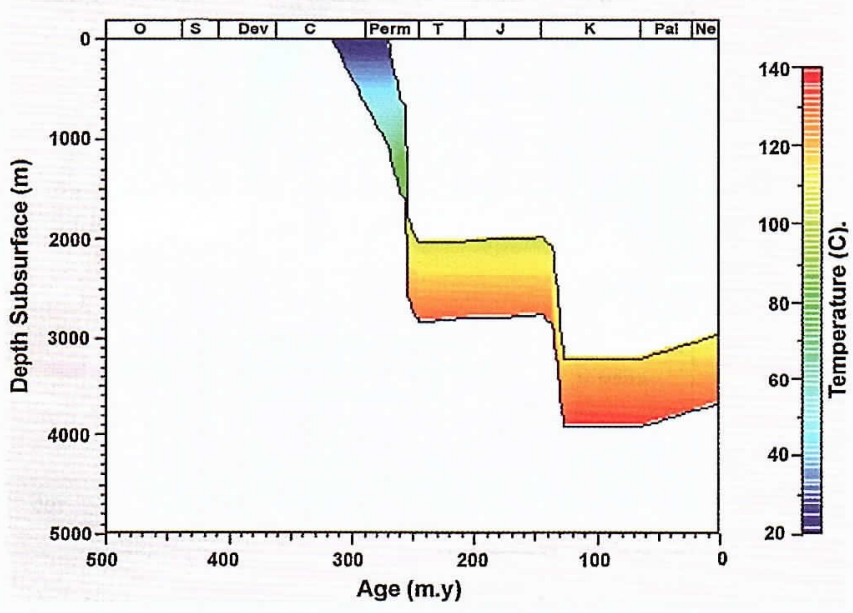

Figura 11 - Temperatura em relação à profundidade, nos arenitos do Grupo Itararé. 
trítico, seleção e profundidade de soterramento, Scherer (1987) desenvolveu uma equação para predição da porosidade. Neste modelo, um arenito do Carbonífero Superior ( $290 \mathrm{Ma}$ ), teria $22 \%$ de porosidade com $1.000 \mathrm{~m}$ de soterramento e $10 \%$ de porosidade a $4.000 \mathrm{~m}$ de soterramento. Na modelagem da história de soterramento, considerando a porosidade e a profundidade alcançada, o resultado obtido para o os arenitos que compõe o Grupo Itararé, foi de $25 \%$ de porosidade na profundidade de $3000 \mathrm{~m}$ e $18 \%$ de porosidade na profundidade de $4000 \mathrm{~m}$ (Fig. 12). Os valores de porosidade obtidos com a modelagem da história de soterramento são semelhantes aos obtidos por meio de cálculos realizados com base em perfis sônicos nos poços selecionados.

A utilização de parâmetros como o índice de fechamento (Kahn 1956) e sua relação com a porosida-

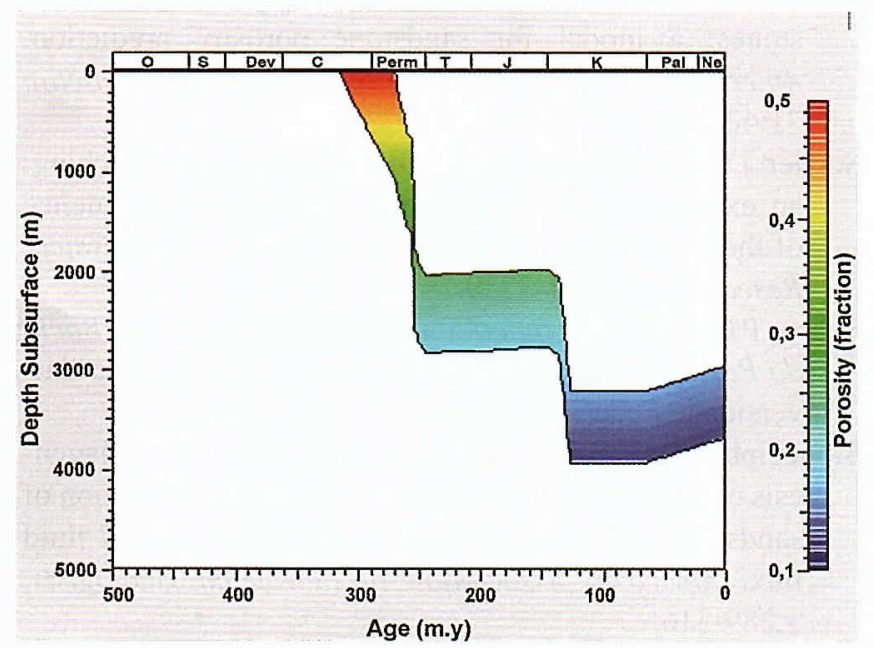

Figura 12 - Porosidade em relação à profundidade, nos arenitos do Grupo Itararé.

de também mostram que o empacotamento é predominantemente fechado $(\mathrm{P}>55)$. A importância relativa dos processos de compactação e de cimentação na redução da porosidade avaliada com a utilização do gráfico de volume intergranular versus cimentação (Houseknecht 1987), indica que a compactação foi mais atuante que a cimentação, na redução da porosidade.

A compactação foi um processo efetivo nos arenitos do Grupo Itararé a partir do Permiano nas seqüências depositadas nas porções mais profundas da bacia e a partir do Eocretáceo nas seqüências mais rasas. Embora ocorra soerguimento durante o Triássico e Jurássico, as modificações diagenéticas tais como, a dissolução de constituintes instáveis, não foi suficiente para geração de porosidade expressiva. A redução de porosidade por compactação logo após a deposição do Grupo Itararé representou um aspecto irreversível na diminuição do sistema poroso e na geometria dos poros.

CONCLUSÕES A abordagem integrada entre a história de soterramento e diagênese do Grupo Itararé na Bacia do Paraná, foi utilizada para compreender o efei- to da compactação em reservatórios de hidrocarbonetos. Foram identificadas quatro fases de subsidência na Bacia do Paraná. A história de soterramento do Grupo Itararé relaciona-se à terceira fase de subsidência da bacia e com sua evolução a partir do Carbonífero-Permiano. Esta fase de subsidência foi atuante na bacia do Permocarbonífero até o início do Triássico e registra a deposição da Seqüência Gondwana I, a qual atingiu uma espessura em torno de $2400 \mathrm{~m}$.

A profundidade de soterramento, bem como o tempo em que uma unidade permanece sob determinadas condições de pressão e temperatura determina a ocorrência das alterações diagenéticas. Neste contexto destaca-se que a deposição do Grupo Itararé relacionase a um período em que ocorreram as maiores taxas de subsidência na Bacia do Paraná. Esta subsidência acentuada teve influência marcante na redução da porosidade por compactação. Com o progressivo aumento da profundidade de soterramento as alterações diagenéticas passam a ser controladas por pressão e temperatura mais elevadas. Este estágio é bem marcado nos arenitos do Grupo Itararé, principalmente pela observação dos efeitos da compactação química, que resulta da dissolução por pressão dos grãos ao longo dos seus contatos. Além da compactação química, na mesodiagênese, sob condições de soterramento efetivo, desenvolveram-se crescimentos sintaxiais de quartzo, cimentação abundante por anidrita, e dissolução parcial de cimentos e componentes detríticos.

$O$ índice de fechamento mostra que o empacotamento em grande parte dos arenitos é fechado ( $>>55)$, com uma estimativa de porosidade em torno de $10 \%$ nos arenitos em profundidades próximas a $4000 \mathrm{~m}$. A importância dos processos de compactação e de cimentação na redução da porosidade mostra que a compactação exerceu maior controle do que a cimentação na redução da porosidade e geometria dos poros. A compactação exerce um controle mais eficiente na redução de porosidade, pois causa modificações irreversíveis para o sistema poroso e atuou nos arenitos do Grupo Itararé a partir do Permiano. A cimentação precoce poderia influenciar na preservação do arcabouço durante o soterramento e posteriormente favorecer um ganho de porosidade por dissolução. Porém, a compactação foi mais efetiva e suas conseqüências dificultaram reações diagenéticas posteriores.

Agradecimentos À PETROBRAS - Petróleo Brasileiro S/A por intermédio do PROFEX, Programa Tecnológico em Fronteiras Exploratórias, em conjunto com a FINEP - Financiadora de Estudos e Projetos do Governo Brasileiro pelo apoio ao Projeto SPHERA - Simulação de Processos Hidrodinâmicos em Reservatórios Análogos na Bacia do Paraná - À UFPR pelo apoio institucional. Ao orientador e coordenador do Projeto SPHERA, Dr. Sidnei Pires Rostirolla pelas oportunidades acadêmicas. Ao Dr. Almério de Barros França pela avaliação técnica e considerações. Aos revisores da RBG pelas sugestões. 


\section{Referências}

Artur P.C. \& Soares P.C. 2002. Paleoestruturas e petróleo na Bacia do Paraná, Brasil. Revista Brasileira de Geociências 32(4):433-448.

Bocardi L.B 2005. Petrologia e aspectos diagenéticos de arenitos reservatórios do Grupo Itararé (CarboniferoPermiano), Bacia do Paraná. Dissertação de Mestrado, Universidade Federal do Paraná, 103p.

Bocardi L.B., Fernandes L.A., Rostirolla S.P., Appi C.J. 2006. Diagênese dos arenitos do Grupo Itararé, Permocarbonífero, Bacia do Paraná. Revista Brasileira de Geociências 36(2):221-231.

Daemon R.F., Quadros L.P., Silva L.C. 1967. Devonian polynology and biostratigraphy of thr Paraná Basin. Boletim Paranaense Geociências. 21/22:99-131.

Ehrenberg S.N., Aagaard P., Wilson M.J., Fraser A.R., Duthie D.M.L. 1993. Depth-dependent transformation of kaolinite to dickite in sandstones of the Norwegian continental shelf. ClayMinerals, 28:325-352.

França A.B. \& Potter P.E. 1989. Estratigrafia, ambiente deposicional do Grupo Itararé (Permocarbonífero), Bacia do Paraná (Parte 2). Bol. Geociências Petrobrás, 3:17-28.

Gama Jr. E.G., Bandeira Jr. A.N., França A. B. 1982. Distribuição espacial e temporal das unidades litoestratigráficas paleozóicas na parte central da Bacia do Paraná. Revista Brasileira de Geociências, 12(4):578-589.

Giles M.R., Stevenson S., Martin S.V. 1992. The reservoir properties and diagenesis of the Brent Group: a regional perspective. In: Morton A.C., Haszeldine R.S., Giles M.R., Brown S. (eds.) Geology of the Brent Group. Special Publications of the Geological Society of London, 61:289-327.

Houseknecht D.W. 1987. Assessing the relative importance of compaction processes and cementation to reduction of porosity in sandstones. American Association of Petroleum Geologists, Bulletin, 71:633-642.

Kahn J.S. 1956. The analysis and distribuition of the properties of packing in sand-size sediments. 1 . On the measurement of packing in sandstones. Journal of Geology, 64:385-395.

Milani E.J., França A.B., Schneider R.L. 1994. Bacia do Paraná. Boletim de Geociências da Petrobrás, 8(1):69-82.

Milani E.J. 1997. Evolução tectono-estratigráfica da Bacia do Paraná e seu relacionamento com a geodinâmica fanerozóica do Gonduana Sul-Ocidental. Tese de Doutoramento, IG, Univ. Federal do Rio Grande do Sul, 255p.

Milani E. J. 2004. Comentários sobre a origem e evolução tectônica da Bacia do Paraná. In: Mantesso-Neto V., Bartorelli A., Carneiro C.D.R., Brito-Neves B.B. (eds.) Geologia do Continente Sul-Americano: Evolução da Obra de Fernando Flávio Marques de Almeida. São Paulo: Editora Beca, p.265-279.

Mizusaki A.M.P., Melo J.H., Vignol M.L., Steemans P. 2002. Vila Maria Formation, Paraná Basin, Brazil - an example of integrated geochronological and palynological dating. Geological Magazine, 139(4):453-463.

Morad S., Al-Aasm I.S., Ramseyer K., Marfil R., Aldahan A.A. 1990. Diagenesis of carbonate cements in PermoTriassic sandstones from the Iberian Range, Spain; evi- dence from chemical and stable isotopes. Sedimentary Geology, 67:281-295.

Morad S., Ben Ismail H.N., De Ros L.F., Al-Aasm I.S., Serrhini N-E. 1994. Diagenesis and formation water chemistry of Triassic reservoir sandstones from southern Tunisia. Sedimentology, 41:1253-1272.

Morad S., Ketzer J.M., De Ros L.F. 2000. Spatial and temporal distribution of diagenetic alterations in siliciclastic rocks: implications for mass transfer in sedimentary basins. Sedimentology, 47:1-27.

Németh K., Martin U., Cssillag G. 2003. Calculation of erosion rates based on remmants of monogenetic alcaline basaltic volcanoes in the Bakony-Balaton Highland Volcanic Field (Western Hungary) of Myo/Pliocene Age. Geolines, 15:102-106.

Scherer M. 1987. Parameters influencing porosity in sandstones: a model for sandstone porosity prediction. American Association of Petroleum Geologists Bulletin, 71:485-491.

Sclater J.G. \& Christie P.A.F. 1980. Continental stretching: an explanation of the post-mid-Cretaceous subsidence of the Central North Sea Basin. Journal of Geophysical Research, 85:3711-3739.

Soares P.C. 1991. Tectônica Sinsedimentar Cíclica na Bacia do Paraná - Controles. Tese para professor titular, Universidade Federal do Paraná, Curitiba, 131p.

Stonecipher S.A., Winn Jr. R.D., Bishop M.G. 1984. Diagenesis of the Frontier Formation, Moxa Arch: A function of sandstone geometry, texture and composition and fluid flux. American Association of Petroleum Geologists, 3:289-316.

Surdam R.C., Boese S.W., Crossey L.J. 1984. The chemistry of secondary porosity. In: McDonald D.A., Surdam R.C. (eds.) Clastic Diagenesis. American Association of Petroleum Geologist Memoir 37:127-149.

Turner S., Regelous M., Kelley S., Hawkesworth C., Mantovani M. 1994. Magmatism and continental break-up in the South Atlantic: high precision Ar/Ar geocronology. Earth and planetary Science Letters, 121:333-348.

Wilson M.D., Stanton P.T. 1994. Diagenetic mechanisms of porosity and permeability reduction and enhancement: Reservoir quality assessment and prediction in clastic rocks. SEPM Society for Sedimentary Geology, Short Course, 30:59-118.

Zalán P.V., Wolff S., Conceição J.C.J., Astolfi M.A.M., Vieira I.S., Appi V.T., Zanotto O.A. 1987. Tectônica e sedimentação da Bacia do Paraná. In: Simpósio Sul Brasileiro de Geologia, 3, Atas, p. 441.

Zalán P.V., Wolff S., Astolfi M.A.M., Vieira I.S., Conceição J.C.J., Appi V.T., Neto E.V.S., Cerqueira J. R., Marques A. 1990. The Paraná Basin, Brazil. Tulsa: American Association of Petroleum Geologists, Bulletin, Memoir 51:681-708.

Manuscrito BR 08

Submetido em 21 de dezembro de 2007 Aceito em 10 de março de 2008 